\title{
Learning outcomes of nursing curriculum in Turkey: a cross-sectional study
}

Sevinç Mersin*, Hülya Saray Kılıç, Özlem İbrahimoğlu

School of Health, Nursing Department, Bilecik Şeyh Edebali University, Gulumbe campus, Bilecik 11210, Turkey

Received: 25 May 2019; Accepted: 31 August 2019; Published: 20 June 2020

Abstract: Objective: To assess the nursing curriculum and point out learning outcomes in Turkey.

Methods: A cross-sectional design was used in this study. This study was conducted between May and June 2017 from 23 undergraduate nursing schools' education programs for one education and academic year's curriculum. The public information of the universities collected from their web sites and learning outcomes of the schools were classified as cognitive, psychomotor, and affective domains.

Results: It appears that half of the basic nursing courses are in the psychomotor domain, and the majority of basic medical sciences courses are in the cognitive domain. Learning outcomes about the affective domain mostly take place in basic nursing courses.

Conclusions: The findings of the results of this study can provide insight into current nursing education and guide new curricula to be developed.

Keywords: curriculum • learning outcomes $\bullet$ nursing care $\bullet$ nursing courses $\bullet$ nursing education

(c) Shanxi Medical Periodical Press.

\section{Introduction}

The International Council of Nurses $(\mathrm{ICN})^{1}$ states that nurses must safeguard, respect, and actively promote people's health rights at all times and in all places. So, for students, the nursing curriculum should be considered in terms of empathy, patient-centeredness, cultural awareness, and probably greater understanding of public health and the social determinants of health. ${ }^{2}$ But, improving effective curriculum has been a challenge. The preparation of nursing curriculum is inadequate to face inequalities and present curriculum challenges because the curriculum is obsolete, defective, and constant. ${ }^{3}$

Nursing education has adopted a standardized curriculum for many years. Standardization in nursing education provides basic education and nursing diplomas for students. Standardization is a path to elevate the educational process and provide better outcomes. ${ }^{4}$ The standardized curriculum consists of fundamentals of nursing. The new curriculum topics of informatics, evidence-based practice, leadership, interdisciplinary collaboration, and quality improvement, allowed for a

How to cite this article: Mersin S, Saray Kılıç H, İbrahimoğlu Ö. Learning outcomes of nursing curriculum in Turkey: a cross-sectional study. Front Nurs. 2020; 2: 129-134. 
more creative, and unique approach to curriculum revision. 5,6 Several curriculum provisions may reflect different educational aims in countries. For example, although the curriculums are many in fundamental, few in practical, and few in the style of traditional medical education in the UK and the US, they are based on education resources, school concepts, and the characteristics of students. ${ }^{5,7}$ Furthermore, nursing education in Australia consists of fundamental nursing, nursing research and application, biological science, social science, and clinical practice. . $^{3}$

The curriculum includes courses that contain all learning and teaching activities guided by school and trainers. ${ }^{9,10}$ Creation of curriculum content correlates with aims and objectives to be met in nursing and associated with which the student should be equipped with nursing information. ${ }^{11}$ Accessing to curriculum targeted output after education affects the quality of nursing care. Nursing education cannot be realized at the desires level even in the most developed school, so, the nursing curriculum and, therefore, the nursing education need to be reviewed. ${ }^{5}$

Nursing educators identify the necessary and stable need to revise the nursing curriculum to provide that nursing students are prepared to care for the public. ${ }^{12}$ The basic knowledge for students is determined by the educators for essential curricular elements and expected outcomes. ${ }^{13}$ Educators depend on principles of curriculum and education, nursing curriculum standards and guidelines, and regional, national, and international health care issues to guide their revisions. Although educators are aware of the changes that need to be made in the current curriculum and have the motivation for these changes, they rarely have access to the work that assesses the outcomes of current nursing education for the changes needed. This study aims to contribute to the field by evaluating nursing learning outcomes. ${ }^{12}$ For this reason, it is essential to reveal the curriculum outcomes to redesign. For this reason, nurse education programs need to redesign and develop this context to produce students who are fit for purpose. This study was planned for assessing the nursing curriculum and to point out learning outcomes in Turkey.

\section{Methods}

\subsection{Study design and setting}

A cross-sectional design was used in this study. This study was conducted between May and June 2017 from Nursing Schools' (undergraduate education) education programs for one education and academic year's curriculum. We used the public information of the universities on the web sites. Learning outcomes of the schools studied were classified on a course basis. Studies were sorted as basic nursing, basic medical, nursing elective, and non-nursing elective courses. Learning outcomes of the schools were classified as cognitive (thinking), psychomotor (physical/kinesthetic), and affective (emotion/ feeling) learning.

Cognitive learning consisted of different stages. These are knowledge, comprehension, application, analysis, synthesis, and evaluation. Learning is a process, and thinking forms are created by the educators for students to pass on to the synthesis and evaluation stages.

Psychomotor learning is the realization of physical skills involving activities related to the brain and muscles. The steps in this domain are imitation, manipulation, correctness/truth, articulation, and adoption/ espousal. The steps in this area are acceptance (perception), being in the reaction (answer), appraisal (valuation), organize, and determination (characterize). It is concluded with performing certain actions by following directions and applying skills, showing skills with the least mistake, coordination of two or more skills, and presenting a high level of skills.

Outcomes about affective learning in nursing education asses the evaluation of sociocultural background of the students themselves and their surroundings, the emotional and biological aspects of existing problems, the narrative, spiritual, and philosophical beliefs, and family issues.

\subsection{Data collection and data analysis}

The inclusion criteria of the study were the accessibility of schools' 2016-2017 education - academic year curriculum and learning outcomes. Frequency and percentage of the data measured for classified learning outcomes are used.

\section{Results}

In Turkey, there were 116 nursing schools, and all of them were evaluated for their 2016-2017 EducationAcademic year curriculum and learning outcomes. Thirty-two schools' 2016-2017 Education-Academic year curriculums were accessed. Twenty-three schools' learning outcomes were created the data of the research. The flowchart of the selection criteria for schools in the study is shown in Figure 1.

The nursing curriculum's main courses were basic nursing, basic medical, nursing elective, and non-nursing elective. Basic nursing courses include fundamentals of nursing, medical nursing, surgical nursing, women's health and obstetrics nursing, children's health and 


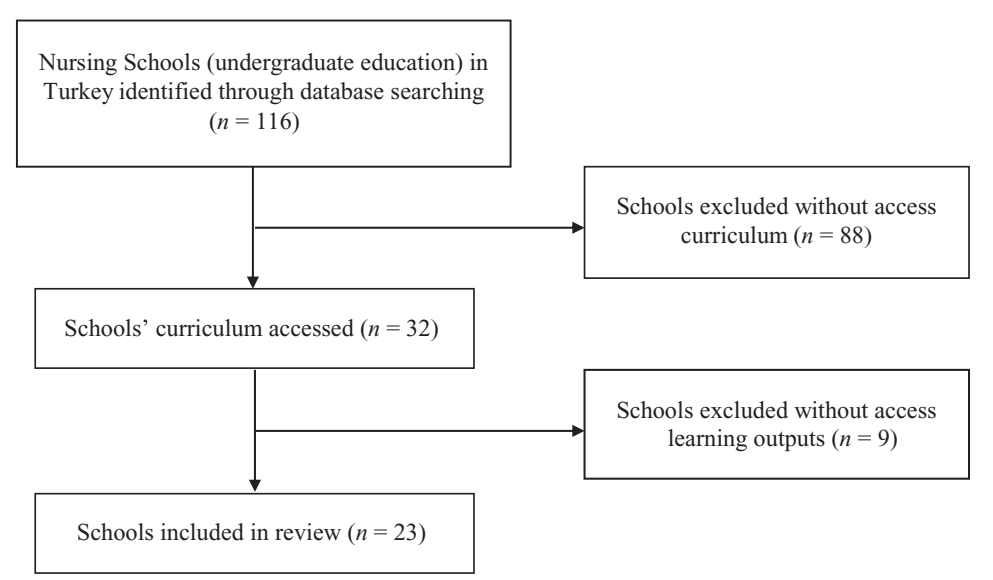

Figure 1. The flow chart of the selection criteria.

\begin{tabular}{llll}
\hline Basic nursing courses & Basic medical courses & Nursing elective courses & Non-nursing elective courses \\
\hline \hline Fundamentals of Nursing & Histology - Pathology & Geriatrics Nursing, Intensive Care Nursing & Physical Education \\
Medical Nursing & General Embryology & Health Sociology, Rehabilitation Nursing & Computer Sciences \\
$\begin{array}{l}\text { Surgical Nursing } \\
\text { Women's Health and }\end{array}$ & Medical Biology and Genetics & Coping Methods, Evidence Based Nursing & Drama and Theatre-Music \\
$\begin{array}{l}\text { Obstetrics Nursing } \\
\text { Children's Health and }\end{array}$ & Epidemiology - Research & Values and Ethics in Nursing, Wound Care & Anthropology \\
Diseases Nursing & Methods and Biostatistics & Nursing & \\
Mental Health Nursing & Infectious Diseases & Family Health Nursing, Dialysis Nursing & Mouth and Dental Health \\
Community Health Nursing & Biochemistry - Pharmacology & Palliative Care, Home Care Nursing & History \\
Nursing Management & Microbiology - Parasitology & Oncology Nursing, Intercultural Nursing & Basic Information Technology \\
Education in Nursing & Anatomy - Physiology & Reproductive Health and Family Planning, & Turkish Language and Literature \\
& & Emergency Care Nursing & \\
\hline
\end{tabular}

Table 1. The courses of nursing education.

diseases nursing, mental health nursing, community health nursing, nursing management, and education in nursing. Basic medical courses include fundamentals about humans. These are Histology-Pathology, General Embryology, Medical Biology and Genetics, Medical Terminology, Epidemiology-Research Methods and Biostatistics, Infectious Diseases, BiochemistryPharmacology, Microbiology-Parasitological, and Anatomy-Physiology. Nursing elective courses include elective about nursing practice. These lessons are about nursing practice but not obligatory. These lessons are geriatrics nursing, intensive care nursing, health sociology, rehabilitation nursing, coping methods, evidence-based nursing, forensic nursing, diabetes nursing, values and ethics in nursing, family health nursing, dialysis nursing, palliative care, home care nursing, oncology nursing, intercultural nursing, reproductive health and family planning, emergency care nursing, and wound care nursing. Non-nursing elective courses include Physical Education, Computer Sciences, Drama and Theater-Music, Anthropology,
Mouth and Dental Health, History, Basic Information Technology, Turkish Language and Literature, and Foreign Language. These courses are given in Table 1.

Table 2 illustrates the classification of education outcomes that are classified as development learning according to nursing. It appears that $52.44 \%(n=796)$ of the basic nursing courses are in the psychomotor domain. It has been determined that $84.05 \%(n=938)$ of basic medical sciences courses are in the cognitive domain. Learning outcomes about the affective domain mostly take place in basic nursing courses as $4.15 \%$ $(n=63)$. It appears that $43.12 \%(n=367)$ of the nonnursing elective courses and $38.47 \%(n=938)$ of nursing elective courses are in the psychomotor domain. It has been determined that $56.29 \%(n=479)$ of the nonnursing elective courses and $58.54 \%(n=843)$ of nursing elective courses are in the cognitive domain. It is seen that the learning outcomes that belong to nursing elective courses and non-nursing elective courses are close to each other in the psychomotor and cognitive domains (Figure 2). 


\begin{tabular}{lccccccccccc}
\hline & \multicolumn{2}{c}{$\begin{array}{c}\text { Basic nursing } \\
\text { courses }\end{array}$} & \multicolumn{2}{c}{$\begin{array}{c}\text { Basic medical } \\
\text { courses }\end{array}$} & \multicolumn{2}{c}{$\begin{array}{c}\text { Nursing elective } \\
\text { courses }\end{array}$} & \multicolumn{2}{c}{$\begin{array}{c}\text { Ton-nursing } \\
\text { elective courses }\end{array}$} \\
\cline { 2 - 9 } & $n$ & $\%$ & $n$ & $\%$ & $n$ & $\%$ & $n$ & $\%$ & $n$ \\
\hline \hline Cognitive domain & 659 & 43.41 & 938 & 84.05 & 843 & 58.54 & 479 & 56.29 & 2919 & 59.27 \\
Psychomotor domain & 796 & 52.44 & 165 & 14.78 & 554 & 38.47 & 367 & 43.12 & 1882 & 38.21 \\
Affective domain & 63 & 4.15 & 13 & 1.17 & 43 & 2.99 & 5 & 0.59 & 124 & 2.52 \\
Total & 1518 & 100 & 1116 & 100 & 1440 & 100 & 851 & 100 & 4925 & 100 \\
\hline
\end{tabular}

Table 2. The classification of learning outcomes.

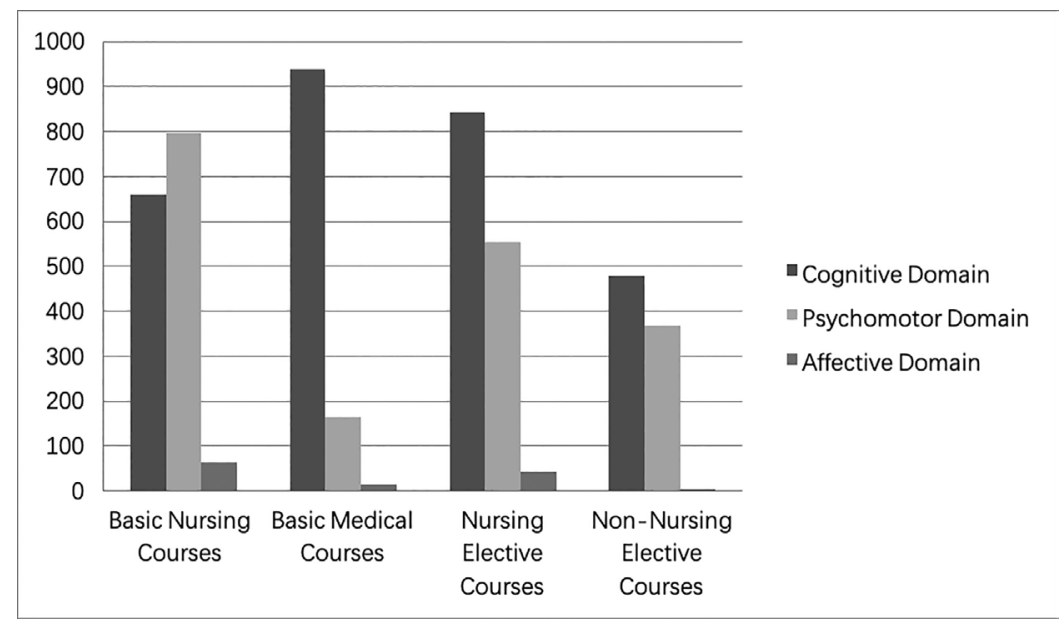

Figure 2. The cross chart of learning outcomes.

\section{Discussion}

This study was planned for assessing the nursing curriculum and to point out learning outcomes in Turkey. The learning outcomes derived in this study from the nursing curriculum have suggested many interesting points beyond the course objectives of all learning and teaching activities that are discussed in this section. A clear and in-depth discussion of the results obtained from this study can provide the completion of deficiencies about cognitive, psychomotor, and affective domains of nursing education that have unrecognized. Thus, by adopting new ideas of cognitive, psychomotor, and affective learning outcomes, nursing ideals can be promoted.

According to the results of this research, a total of 4,925 learning outcomes were obtained after examining the learning outcomes of the 23 nursing schools in Turkey. Most of these outcomes were related to the cognitive domain. Outcomes of the most cognitive domains were found to be related to basic medical courses. Cognitive outcomes have been found at least in basic nursing courses.

The cognitive dimension of nursing education consists of processes, which is from simple to complex, from easy to difficult, from tangible to intangible, and processes of remembering, understanding, analyzing, evaluating, and treating each other as preliminary conditions. ${ }^{14}$ Teaching basic concepts in the nursing education process and basic knowledge for nursing

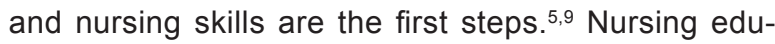
cators utilize and synthesize the best evidence to inform their clinical practice and theoretical training for nursing students, so they apply decision-making skills to provide the best care for the public. ${ }^{15}$ According to the Canadian Nurse Association, ${ }^{16}$ "decision making in nursing practice is influenced by evidence and also by individual values, client choice, theories, clinical judgement, ethics, legislation, and practice environment."

Evaluation of cognitive outcomes involves the utilization and synthesis of theoretical knowledge. ${ }^{17,18}$ When the results of cognitive outcomes obtained from basic nursing courses are evaluated, it showed having problems in recall, understanding, practice, analysis, evaluation, and creation processes. These steps in the cognitive field have been shown to cause inadequacy of critical thinking, low self-esteem, logic, intuition, ingenuity, and synthesis to solve identified problems. ${ }^{19,20}$ The evaluation of cognitive outcomes and the identification 
of the inadequacies associated with this field may help to reduce the gap between theoretical and clinical practice, which is an important problem in nursing education. ${ }^{21}$ Clinical practice skills are an important component of fundamental nursing courses which is about cognitive outcomes. ${ }^{18}$ In nursing education, the establishment of a behavioral and theoretical relationship and the evaluation of this relationship provide the creation of a safe environment for the students and their caregivers. For example, in clinical care, when effective nursing care is provided by the student nurses, students can not only apply the theoretical knowledge but also develop it by synthesizing while using this knowledge. As a result, students learn to develop nursing care according to new situations and different patients. ${ }^{22}$ The success of this process and the project of excellent care to the public increase self-confidence, motivation, positive image and professionalism of nursing students because it enhances their ability to plan, implement, and evaluate care. ${ }^{18}$

According to the results of this study, half of the basic nursing courses were psychomotor learning outcomes. According to this result, it appears that approximately half of the outcomes of the nursing curriculum focus on measuring psychomotor outcomes alone.

The psychomotor domain focuses on physical skills involving the coordination of brain functions and muscle movements. Evaluations of this field can be more concrete, measurable, and observable than cognitive and affective domains. It has focused on the end, not on the process..$^{9,18}$ Psychomotor skills in nursing education gain importance, especially in clinical education. Students mature the information they learn in the theoretical courses through their mental processes and turn them into motor behavior on the patient with the help of their muscles. ${ }^{23}$

Nursing educators guide the theoretical knowledge applied to the clinic as a psychomotor skill and the best decision for the patient by the students. ${ }^{24}$ They have an important role in supporting nursing student's learning during clinical practice. ${ }^{23,25}$ The development and support of nursing students' abilities on the patient are recommended in all areas of nursing. This idea begins to be accepted by both educators and students as soon as nursing education begins. In the psychomotor field, being behavioral outcomes more tangible, measurable, and observable for student assessment can lead to more involvement of behavioral outcomes in the nursing education curriculum. ${ }^{26}$

Affective learning outcomes were not sufficient in this study. Although the outcomes of affective learning outcomes are mostly related to basic nursing courses, it is determined that they are much lower than psychomotor and cognitive learning outcomes compared to total learning outcomes.

Teaching affective skills ensure assessing nursing students' personal reactions to themselves, patients and other nurses, planning and implementing effective initiatives; reducing self-criticism and increasing empowerment with reinforcement skills; selecting the best assessment tools to determine patients' dilemmas and reactions; identifying the reactions that are taking place to alleviate nonadaptive feelings; increasing awareness of reactions that affect objectivity; and understanding the reactions of colleagues to improve their profession. 27,28 Recognizing the inadequacy of outcomes related to the affective domain and making necessary arrangements affect positively the development of skills such as self-confidence, autonomy, coping and adaptation to the situation, and creating a motivational lifestyle. It also allows for the development of professional skills, increased job and life satisfaction, reduced burnout emotions and mental disorders. ${ }^{27}$

\section{Conclusions}

Identification of learning outcomes and presentation of results are one of the important roles of educators. Questioning of educational outcomes in nursing education is the need for the development of curriculum programs for safe and quality care. Nursing students need policy and training activities to improve their competence and develop their skills. The growing need for nurses and patients creates challenges for the nursing curriculum. So, there is a scope for international collaboration and research. Research-based recommendations for nursing education may be useful in enhancing the quality of nursing education. Collaboration between undergraduate nursing curriculum and clinical practice is necessary to ensure that the relevant content of basic nursing, basic medical, nursing elective, and non-nursing elective courses is provided during nurses' basic education with contemporary and evidence-based methods. It is also important to create opportunities for educators to update and improve the nursing curriculum to increase the quality and contemporaneity of nursing education. In the future, it would be exciting to identify the educational preparation of nursing educators responsible for the nursing curriculum. The amount and diversity of learning outcomes are different between nursing curriculums. One way for addressing this problem is the development of nationally and internationally guided curriculum recommendations. The findings of the results of this study can provide insight into current nursing education and guide new curricula to be developed. 


\section{Ethical approval}

Ethical issues are not involved in this article.

\section{Conflicts of interest}

All contributing authors declare no conflicts of interest.

\section{References}

1. International Council of Nurses. Position Statement: Nurses and Human Rights. 2011. http://www. icn.ch/images/stories/documents/publications/position_statements/E10_Nurses_Human_Rights.pdf. Accessed June 2, 2018.

2. Jones $\mathrm{R}$, Young $\mathrm{K}$, Munro $\mathrm{J}$, et al. Including the online feedback site, patient opinion, in the nursing curriculum: exploratory study. Nurse Educ Today. 2017:57:40-46.

3. Rozendo CA, Salas AS, Cameron B. A critical review of social and health inequalities in the nursing curriculum. Nurse Educ Today. 2017;50:62-71.

4. Roberts L. Should the NP curriculum be standardized? Yes. J Nurs Pract. 2018;14:140.

5. Deng FF. Comparison of nursing education among different countries. Chin Nurs Res. 2015;2:96-98 (in Chinese).

6. Murray S, Kimberly L, Gontarz J. Evaluation of a concept-based curriculum: a tool and process. Teach Learn Nurs. 2015;10:169-175.

7. Bosek MS. Critique of advance directives: curriculum content and preparation of nursing students. Medsurg Nurs. 2007;16:191-192.

8. Wang $\mathrm{ZX}, \mathrm{Hu} \mathrm{CH}$. Enlightenment of contrast of undergraduate nursing educational characteristics between in China and in Australia on undergraduate nursing education in China. Chin Nurs Res. 2013;27:1142-1148 (in Chinese).

9. Brown LP. Revisiting our roots: caring in nursing curriculum design. Nurse Educ Pract. 2011;11:360-364.

10. Zengin N, Yazici S, Karanisoglu H. Curriculum integration evaluation scale: development and psychometric testing. Electron J Vocation Coll. 2012;December:151-159.

11. Atalay $\mathrm{M}, \mathrm{Tel} \mathrm{H}$. A vision of baccalaureate and graduate nursing education: the next decade. J Cumhuriyet Univ Sch Nurs. 1999;3:47-54.

12. Nosek CM, Scheckel MM, Waterbury T, Macdonald A, Wozney N. The collaborative improvement model: an interpretive study of revising a curriculum. J Prof Nurs. 2017;33:38-50.

13. Hande K, Williams CT, Robbins HM, Kennedy BB, Christenbery T. Leveling evidence-based practice across the nursing curriculum. J Nurse Pract. 2017;13:17-22.

14. Skuballa IT, Dammert A, Renkl A. Two kinds of meaningful multimedia learning: is cognitive activity alone as good as combined behavioural and cognitive activity? Learn Instr. 2018;54:35-46.

15. Mackey A, Bassendowski S. The history of evidence-based practice in nursing education and practice. J Prof Nurs. 2017;33:51-55.

16. Canadian Nurses Association. Evidence-based decision-making and nursing practice. 2002. http:// www.nurseone.ca/-/media/nurseone/page-content/ pdf-en/ps63_evidence_based_decision_making_ nursing_practice_e.pdf?la=en. Accessed June 2, 2018.

17. Krathwohl DR. A revision of Bloom's taxonomy: an overview. Theory Pract. 2002;41:211-218.

18. Stroup C. Simulation usage in nursing fundamentals: integrative literature review. Clin Simul Nurs. 2014;10:155-164.

19. Butler HA, Dwyer CP, Hogan MJ, et al. The Halpern critical thinking assessment and real-world outcomes: cross-national applications. Thinking Skills Creativity. 2012;7:112-121.

20. Wechsler SM, Saiz C, Rivas SF, et al. Creative and critical thinking: independent or overlapping components? Thinking Skills Creativity. 2018;27:114-122.

21. Dohrn J, Desjardins K, Honig, J, et al. Transforming nursing curricula for a global community. J Prof Nurs. 2018;34:449-453.

22. Yoo MS, Yoo IY. The effectiveness of standardized patients as a teaching method for nursing fundamentals. J Nurse Educ. 2003;42:444-448.

23. Sulosaari V, Huupponen R, Torniainen K, Hupli M, Puukka P, Leino-Kilpi H. Medication education in nursing programmes in Finland-Findings from a national survey. Collegian. 2014;21:327-335.

24. Honey M, Lim AG. Application of pharmacology knowledge in medication management by final year undergraduate nursing students. Contemp Nurse. 2008;30:12-19.

25. Lannan SA. Nursing program evaluation for nurse educators. Nurse Educ Today. 2017;55:17-19.

26. Jaafarpour M, Aazami S, Mozafari M. Does concept mapping enhance learning outcome of nursing students? Nurse Educ Today. 2016;36:129-132.

27. Cam O, Buyukbayram A. Nurses' resilience and effective factors. J Psychiatr Nurs. 2017;8:118-126.

28. Gorman LM, Sultan DF. Psychosocial Nursing for General Patient Care. Philadelphia, USA: FA. Davis Company; 2008. 